\title{
EFFICACY OF ULTRASONIC LIPOLYSIS ON BLOOD CHOLESTEROL LEVEL IN CENTRALLY OBESE WOMEN
}

\section{Mohamed Hussien ElGendy *1, Abir Zakaria Mohamed 2, Yasser Ramzy Lasheen ${ }^{3}$,} Mustafa Awad Ali Awad 4 .

*1 Professor of Physical therapy for Basic Science Department, Faculty of physical therapy - Cairo University, Egypt.

${ }^{2}$ Professor of Int. Medicine, Faculty of Medicine, Cairo University, Egypt.

${ }^{3}$ Lecturer of Physical Therapy Basic Science Department, Faculty of Physical Therapy- Cairo University, Egypt.

${ }^{*}$ Physical therapist, BSc. of physical therapy physical therapy for Basic Science Department, Faculty of physical therapy - Cairo University, Cairo, Egypt.

\section{ABSTRACT}

Background and purpose: fat located within the abdominal cavity; is the best correlate of most of metabolic complications that accounts to a large extent for the increased risk of cardiovascular disease. Ultrasonic Lipolysis is a well-recognized and a successful treatment method in a management of localized fat removal, hence the purpose of this study was to investigate the effect of Ultrasonic Lipolysis on BMI, waist circumference, WHR and blood cholesterol level in centrally obese women.

Materials and Methods: Forty obese Women with centrally obesity, aged 30 to 40 years, with BMI $\geq 30 \mathrm{Kg} / \mathrm{m} 2$; waist circumference $\geq 88 \mathrm{~cm}$ and waist hip ratio $\geq 0.9$ participated in the study. Subjects were randomly assigned into 2 groups; study with 20 women received ultrasonic lipolysis two times, at an eight week interval, as well as low caloric low fat diet (1200-1500 cal/day) \& abdominal exercise ( 3 times per week) for eight consecutive weeks. The control group with 20 women received only low caloric, low fat diet (1200-1500 calories/day) \& abdominal exercise ( 3 times per week) for eight consecutive weeks. Weight height scale was used to measure body weight \& height, a tape measurement was used to determine the waist and hip circumference. A blood sample was taken to determine blood cholesterol levels. All measurements were obtained in the first intervention session (pre-intervention) and after the last session (post-intervention).

Results: When comparing both groups post-test; there was no significant difference for body weight and BMI, where $t$ and $p$ values were $(-.58),(0.56)$ and $(-.91),(0.36)$. However, waist circumference, waist hip ratio and blood cholesterol levels showed significant differences with $t$ and $p$ value $(-4.44)(0.0001),(-16.07)(0.0001)$ and (2.71) (.01) respectively.

Conclusion: Ultrasonic lipolysis had a significant effect on reducing abdominal fat by its significant decrease in waist circumference ; waist hip ratio; and blood cholesterol levels in obese centrally women.

KEY WORDS: Ultrasonic lipolysis, body mass index, waist to hip ratio.

Address for correspondence: Dr. Mustafa Awad Ali Awad, Physical therapist, BSc. of physical therapy physical therapy for Basic Science Department, Faculty of physical therapy-Cairo University, Cairo, Egypt. E-Mail: awadmustafa442@gmail.com

\section{Access this Article online}

Quick Response code

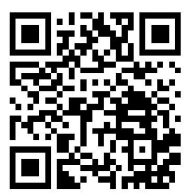

DOI: $10.16965 /$ ijpr.2017.163
International Journal of Physiotherapy and Research

ISSN 2321- 1822

www.ijmhr.org/ijpr.html

Received: 18-04-2017

Peer Review: 20-04-2017

Accepted: 13-05-2017

Revised: None
Published (0): 20-07-2017

Published (P): 11-08-2017

\section{INTRODUCTION}

Obesity is the most common metabolic disorder in human: there are many etiological causes for obesity. Excess fat accumulation caused by imbalance between energy intake and expenditure [1]. 
Abdominal obesity is known as belly fat or clinically as central obesity, is the accumulation of abdominal fat resulting in an increase in waist size. There is a strong correlation between central obesity and cardiovascular disease [2].

Fat distribution may be more important to health than the total amount of body fat. It is well established that fat distributed in the trunk and especially intra-abdominal adipose tissue is related to the development of diabetes and heart disease, as well as mortality. Whereas, fat distributed in the legs appears to impose little or no risk [3].

The most widely used index of obesity is (BMI) which correlates well both the direct measures of fatness, morbidity and mortality. Body mass index = weight in $\mathrm{Kg} /$ height in $\mathrm{m}^{2}$ [4].

The vibrations, which the ultrasound carries cavitation fires into the deep tissue, enable the fat cells to open up, the lymph picks up all waste products excreted by the fat cell, and they are discharged from the body with urine [5].

The fat from opened cells is released into blood flow, where it is used as an energy source. This is also the reason why therapist always recommends that this therapy is followed by some form of physical exercise [5].

The cavitation used in the field of aesthetic medicine is an innovative technique for a non-surgical reduction of the localized fat and cellulite, Ultrasonic vibrations spread in the form of a wave in medium such as a liquid or a solid. When the particles of an elastic medium are under ultrasounic vibration, they act continuously in only one direction [6].

This phenomenon called cavitation, and is a very smart way to reduce fat because it is convert the fat into liquid and then is naturally eliminated with the urine when cavitation therapy is followed by lymphatic drainage.; the process is faster and the drainage is very effective [7].

Completely non-invasive and painless, and it consists of three important phases, opening the lymph paths, ultrasound cavitation therapy and final drainage. It reduces the cellulite, increases the lymph flow, improves the skin tonus, reduces visible capillaries, and helps to decrease the body size [5].

After disruption of the fat cells, the contents, Int J Physiother Res 2017;5(4):2164-70. ISSN 2321-1822 primarily triglycerides (TG), are dispersed into interstitial space and then transported through the vascular lymphatic system to the liver. These triglycerides are theoretically absorbed slowly and then metabolized by endogenous lipases to glycerol and free fatty acids. The fatty acids are transported to the liver where they are processed like any other fatty acids [8].

Obesity often increases the risk of heart disease because of its negative effect on blood lipid levels, which increase in obese patients and then, in turn, increase TG levels and decrease High Density Lipoprotein cholesterol (HDL-C) or "good cholesterol, People with an excessive amount of body fat have higher levels of TG and low Density Lipoprotein cholesterol (LDL-C) or "bad cholesterol" - as well as lower levels of HDL-C in the blood. This recipe creates optimal conditions for developing heart disease [9].

\section{MATERIALS AND METHODS}

Forty women with age range $30-40$ years would participate in this study. For the purpose of this research, this age range would be chosen to exclude pre-menopausal as well as menopausal women to limit any factors as hormonal disturbances that may interfere with weight loss. The cause of obesity was limited to behavioral and environmental factors (i.e., sedentary lifestyles combined with excess energy intake).

Inclusive Criteria: Women with age range from 30-40 years old [10]. Women with regular menstrual cycles would be included. Women exceeding BMI of $30 \mathrm{~kg} / \mathrm{m} 2$, waist circumference more than $88 \mathrm{~cm}$, waist to hip ratio more than 0.9 and having lower abdominal obesity (fat collection) were be selected. Each subject would be signed a consent form prior to intervention procedure.

Exclusive criteria: Lesions of higher center leading to obesity, Pregnant, lactating, diabetic or single women, Women with History of cesserian section, History of liver disease, History of active or chronic infectious, autoimmune disease, Coagulation disorders or on anti-coagulant drugs, Any postural abnormalities (as scoliosis, kyphosis, etc...), Extreme skin laxity, History of abdominal surgeries.

Design of study: Pre test -post test research 
design with control. This study would be conducted at two private clinics. Meeting the participants once a week in the clinic for measuring body weight and change the diet regimen, three times a week for abdominal exercises and after eight weeks for measuring waist circumference, calculate body mass index and waist hip ratio. The blood sample would be taken before starting the intervention and after eight weeks at the end of the intervention.

First, searching for the ideal subjects for this study as young obese women with localized abdominal fat, and then talking to the women about the study for convincing them to participate in the study which may take from half an hour to an hour to be convinced or not.

Finally Forty (40) women with BMI exceeding $30 \mathrm{~kg} / \mathrm{m} 2$, waist circumference exceeding 88 $\mathrm{cm}$, waist to hip ratio exceeding 0.9.

After acceptance of the participant to be introduced in the study and signing on the consent form, pre-test and post-test design was used, were participants randomly assigned into two groups:

Study Group: Included twenty women who would receive non invasive external ultrasonic lipolysis two times per week, at an eight week interval as well as low caloric low fat diet (1200$1500 \mathrm{cal} /$ day) \& abdominal exercise (3 times per week) for eight consecutive weeks

Control Group: Included twenty women who received low caloric, low fat diet (1200-1500 calories/day) \& abdominal exercise (3 times per week) for eight consecutive weeks.

Body weight and waist circumference would be measured, body mass index and waist to hip ratio would be calculated and blood sample would be taken before and after the intervention for all participants.

\section{Evaluative instrumentation:}

Weight and Height scale: For measuring weight in $\mathrm{kg}$ and height in $\mathrm{cm}$ to calculate the body mass index (BMI) by dividing weight in $\mathrm{kg}$ on Height in meter square .

Non stretchable Tape Measurement: For measuring waist circumference (WC) in $\mathrm{cm}$ and hip circumference in $\mathrm{cm}$ and then calculate waist to hip ratio (WHR).
Evaluative procedure: All measurements were taken prior to the intervention procedure as a pretest measure and after 8 consecutive weeks; after the termination of the intervention procedure as a post-test measure.

\section{Obesity measurements:}

Weight \& Height scale: the subject stood straight on the scale while the weight was measured in kilograms and height in centimeters.

Body mass index: was then calculated by the weight in kilograms divided by the square of the height in meters.

Waist Circumference: that was measured just about the crest of the upper hip bones by a tape measurement

Waist Hip Ratio: Using a non-stretchable tape, the hips was measured at the widest part of the hip bones, and the waist was measured just about the crest of the upper hip bones, then the WHR was calculated by dividing the waist measurement by the hip measurement.

Blood Cholesterol measurement: A twelve hour fasting blood sample will collected from the patient to measure blood cholesterol level prior to the intervention procedure as a pre-test measure and after 8 consecutive weeks after the termination of the intervention procedure as a post-test measure.

Therapeutical instrumentation: Ultrasound cavitations device

Treatment Procedure: By using low frequency ultrasound machine (luvatra). The patient was in supine lying position. The session was on the abdominal area. Gel on fleshy parts was applied. The amount depends on moving flexibility of the ultrasound. Set work time was $25 \mathrm{~min}$, output in intensity was regulated at $40 \mathrm{~W} / \mathrm{Cm}^{2}$. Click "start author held the ultrasound head to move slowly on skin, in circle movement. Enough gel was needed; patient might feel painful if medium is not enough. The machine would pause automatically if the setting time was over. The leftovers were cleaned with hot towel and warm towel was used to clean the ultrasound head. The procedure was repeated 2 times per week for 2 months.

\section{RESULTS}

Forty obese women participated in the study. 
Subjects were subdivided into two matched groups; twenty subjects in each group. The first group was the study group who received ultrasonic lipolysis, diet and exercises; the second group was the control group who received diet and exercises.

Data obtained from both groups regarding weight, BMI, waist circumference, WHR, and cholesterol before initiation and following the treatment program were statistically analyzed and compared.

\section{General characteristics of the subjects:}

Study group: Twenty obese women were included in this group. Their mean \pm SD age, weight, height, and BMI were $34.55 \pm 3.41$ years, $96.18 \pm 9.15 \mathrm{~kg}, 164.6 \pm 5.45 \mathrm{~cm}$, and $35.56 \pm$ $3.75 \mathrm{~kg} / \mathrm{m}^{2}$ respectively as shown in table (1) and figure (1).

Control group: Twenty obese women were included in this group. Their mean \pm SD age, weight, height, and BMI were $35.05 \pm 3.34$ years, $95.97 \pm 9.44 \mathrm{~kg}, 163.45 \pm 4.08 \mathrm{~cm}$, and $35.96 \pm$ $3.67 \mathrm{~kg} / \mathrm{m}^{2}$ respectively as shown in table (2) and figure (2).

Comparing the general characteristics of the subjects of both groups revealed that there was no significance difference between both groups in the mean age, weight, height, or BMI $(p>0.05)$.

Table 1: Descriptive statistics and t-test for comparing the mean age, weight, height, and BMI of study and control groups.

\begin{tabular}{|l|c|c|c|c|c|c|}
\hline & Study group & Control group & \multirow{2}{*}{ MD } & \multirow{t}{*}{ - value } & p-value & Significance \\
\cline { 2 - 3 } & $\bar{X} \pm S D$ & $\bar{X} \pm S D$ & & & & \\
\hline Age $($ years) & $34.55 \pm 3.41$ & $35.05 \pm 3.34$ & -0.5 & -0.46 & 0.64 & NS \\
\hline Weight $(\mathrm{kg})$ & $96.18 \pm 9.15$ & $95.97 \pm 9.44$ & 0.21 & 0.07 & 0.94 & NS \\
\hline Height $(\mathrm{cm})$ & $164.6 \pm 5.45$ & $163.45 \pm 4.08$ & 1.15 & 0.75 & 0.45 & NS \\
\hline BMI $\left(\mathrm{kg} / \mathrm{m}^{2}\right)$ & $35.56 \pm 3.75$ & $35.96 \pm 3.67$ & -0.4 & -0.33 & 0.73 & NS \\
\hline $\bar{X}_{\text {: mean }}$ & SD: Standard Deviation MD: mean difference
\end{tabular}

t value: Unpaired $t$ value $p$ value: Probability value NS: Non significant

BMI:

Post treatment mean values of BMI of both groups (study and control): The mean \pm SD BMI post treatment of study group was $29.93 \pm 3.49$ $\mathrm{kg} / \mathrm{m}^{2}$ and that of control group was $30.94 \pm 3.48$ $\mathrm{kg} / \mathrm{m}^{2}$. The mean difference between both groups was $-1.01 \mathrm{~kg} / \mathrm{m}^{2}$. There was no significant difference in the mean values of BMI between study and control groups post treatment $(p=0.36)$. (Table $10 \&$ figure 32$).$

Table 2: $T$ test for comparison between post treatment mean values of BMI of study and control groups:

\begin{tabular}{|c|c|c|c|c|c|}
\hline & $B M I\left(k g / m^{2}\right)$ & \multirow{2}{*}{ MD } & t- value & p-value & Sig \\
\cline { 2 - 2 } & $\overline{\mathrm{X}} \pm \mathrm{SD}$ & & & & \\
\hline Study group & $29.93 \pm 3.49$ & \multirow{2}{*}{-1.01} & -0.91 & 0.36 & NS \\
\hline Control group & $30.94 \pm 3.48$ & & & & \\
\hline
\end{tabular}

$\bar{X}:$ Mean $\quad$ MD :Mean difference $p$ value : Probability value

SD :Standard deviation tvalue : Unpaired tvalue NS : Non significant

Fig. 1: Post treatment mean values of BMI of study and control groups.

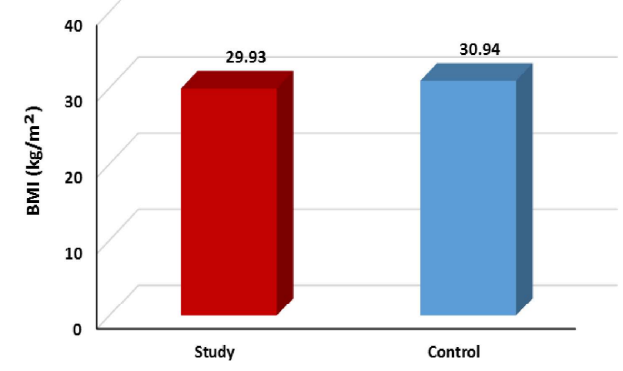

Waist circumference:

Post treatment mean values of waist circumference of both groups (study and control): The mean \pm SD waist circumference post treatment of study group was $83.35 \pm 6.3 \mathrm{~cm}$ and that of control group was $94.85 \pm 9.71 \mathrm{~cm}$. The mean difference between both groups was -11.5 $\mathrm{cm}$. There was a significant decrease in the mean values of waist circumference of study group compared with control group post treatment $(p=0.0001)$. (Table $3 \&$ figure 2$)$.

Table 3: $T$ test for comparison between post treatment mean values of waist circumference of study and control groups:

\begin{tabular}{|c|c|c|c|c|c|}
\hline & \begin{tabular}{|c|}
$\begin{array}{c}\text { Waist circumference } \\
(\mathrm{cm})\end{array}$ \\
\end{tabular} & \multirow[t]{2}{*}{ MD } & \multirow[t]{2}{*}{$t$-value } & \multirow[t]{2}{*}{ p-value } & \multirow[t]{2}{*}{ Sig } \\
\hline & $\bar{x} \pm S D$ & & & & \\
\hline Study group & $83.35 \pm 6.3$ & \multirow{2}{*}{-11.5} & \multirow{2}{*}{-4.44} & \multirow{2}{*}{0.0001} & \multirow{2}{*}{$\mathrm{s}$} \\
\hline Control group & $94.85 \pm 9.71$ & & & & \\
\hline $\begin{array}{ll}\overline{\mathrm{X}} & : \text { Mean } \\
\text { SD } & : \text { Standard dev }\end{array}$ & 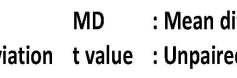 & $\begin{array}{l}\text { erence } \\
\text { t value }\end{array}$ & $\begin{array}{l}p \text { value } \\
S\end{array}$ & $\begin{array}{l}\text { Probability } \\
\text { ignificant }\end{array}$ & lue \\
\hline
\end{tabular}

Fig. 3: Post treatment mean values of BMI of study and control groups.

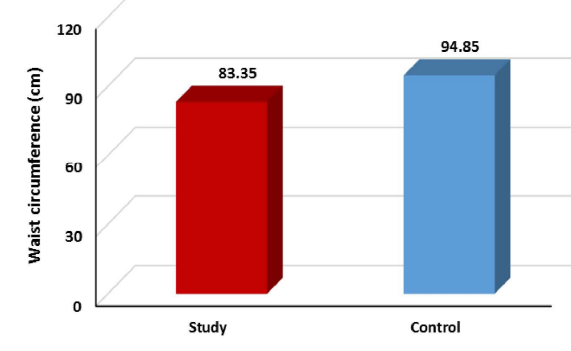




\section{WHR}

Post treatment mean values of WHR of both groups (study and control): The mean \pm SD WHR post treatment of study group was $0.71 \pm$ 0.01 and that of control group was $0.86 \pm 0.03$. The mean difference between both groups was -0.15 . There was a significant decrease in the mean values of WHR of study group compared with control group post treatment $(p=0.0001)$. (Table 4 \& figure 4 ).

Table 4: $T$ test for comparison between post treatment mean values of WHR of study and control groups:

\begin{tabular}{|c|c|c|c|c|c|}
\hline & WHR & \multirow{2}{*}{ MD } & \multirow{2}{*}{ t- value } & \multirow{2}{*}{$p$-value } & \multirow{2}{*}{ Sig } \\
\hline & $\bar{\Psi} \mathrm{ESD}$ & & & & \\
\hline Study group & $0.71 \pm 0.01$ & \multirow{2}{*}{-0.15} & \multirow{2}{*}{-16.07} & \multirow{2}{*}{0.0001} & \multirow{2}{*}{$\mathbf{S}$} \\
\hline Control group & $0.86 \pm 0.03$ & & & & \\
\hline $\bar{X} \quad$ :Mean & ML & & p valu & : Prol & we \\
\hline SD : Standard devi & ion tvalue : & oaired t va & de $S$ & : Significant & \\
\hline
\end{tabular}

Fig. 4: Post treatment mean values of WHR of study and control groups.

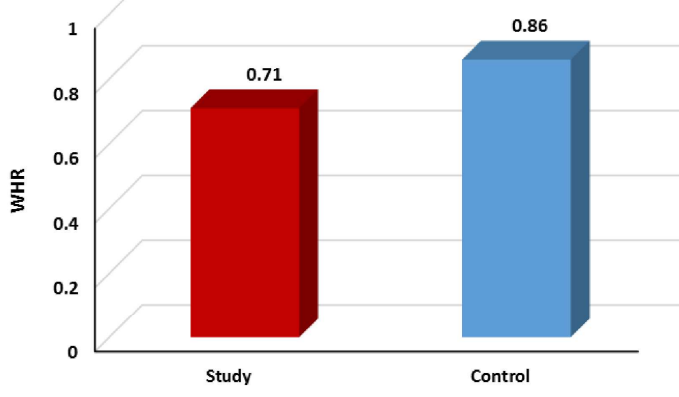

\section{Cholesterol}

Pre treatment mean values of cholesterol of both groups (study and control): The mean \pm SD cholesterol pre treatment of study group was $221.25 \pm 9.29 \mathrm{mg} / \mathrm{dl}$ and that of control group was $218.2 \pm 9.5 \mathrm{mg} / \mathrm{dl}$. The mean difference between both groups was $3.05 \mathrm{mg} / \mathrm{dl}$. There was no significant difference in the mean values of cholesterol between study and control groups pre treatment $(p=0.31)$. (Table $5 \&$ figure 5$)$.

Table 5: $T$ test for comparison between pre treatment mean values of cholesterol of study and control groups:

\begin{tabular}{|c|c|c|c|c|c|}
\hline & $\begin{array}{c}\text { Cholesterol } \\
\text { (mg/dl) }\end{array}$ & \multirow{2}{*}{ MD } & t- value & p-value & Sig \\
\cline { 2 - 2 } & $\overline{\bar{X}}$ SD & & & \\
\hline Study group & $221.25 \pm 9.29$ & \multirow{2}{*}{3.05} & 1.02 & 0.31 & NS \\
\hline Control group & $218.2 \pm 9.5$ & & & \\
\hline
\end{tabular}

$\bar{X}:$ Mean $\quad$ MD :Mean difference $p$ value :Probability value

SD :Standard deviation tvalue :Unpaired tvalue NS :Non significant
Fig. 5: Pre treatment mean values of cholesterol of study and control groups.

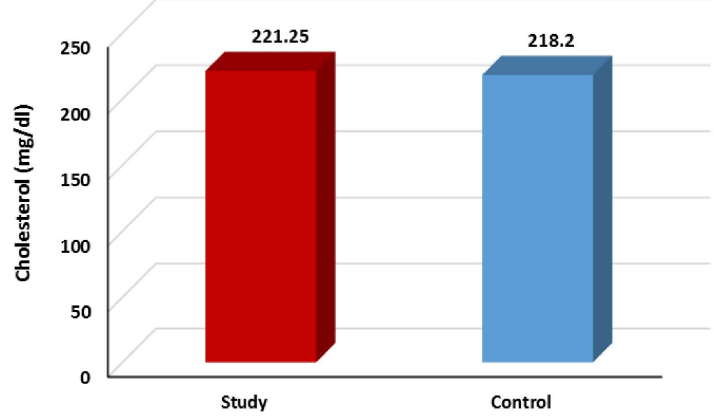

Post treatment mean values of cholesterol of both groups (study and control): The mean \pm SD cholesterol post treatment of study group was $172.95 \pm 8.45 \mathrm{mg} / \mathrm{dl}$ and that of control group was $180.65 \pm 9.46 \mathrm{mg} / \mathrm{dl}$. The mean difference between both groups was $-7.7 \mathrm{mg} /$ dl. There was a significant decrease in the mean values of cholesterol of study group compared with control group post treatment $(p=0.01)$. (Table 6 \& figure 6 ).

Table 6: $T$ test for comparison between post treatment mean values of cholesterol of study and control groups:

\begin{tabular}{|c|c|c|c|c|c|}
\hline & $\begin{array}{c}\text { Cholesterol } \\
(\mathrm{mg} / \mathrm{dl})\end{array}$ & MD & $\mathrm{t}$ - value & $\mathrm{p}$-value & $\mathrm{S}$ Sig \\
\hline & $\overline{\mathrm{X}} \pm \mathrm{SD}$ & & & \\
\hline Study group & $172.95 \pm 8.45$ & -7.7 & -2.71 & 0.01 & $\mathrm{~S}$ \\
\hline Control group & $180.65 \pm 9.46$ & & \multicolumn{3}{|c|}{ :Mean difference p value :Probability value } \\
\hline $\bar{X}$ : Mean
\end{tabular}

SD :Standard deviation tvalue : Unpaired tvalue $S$ :Significant

Fig. 6: Post treatment mean values of cholesterol of study and control groups.

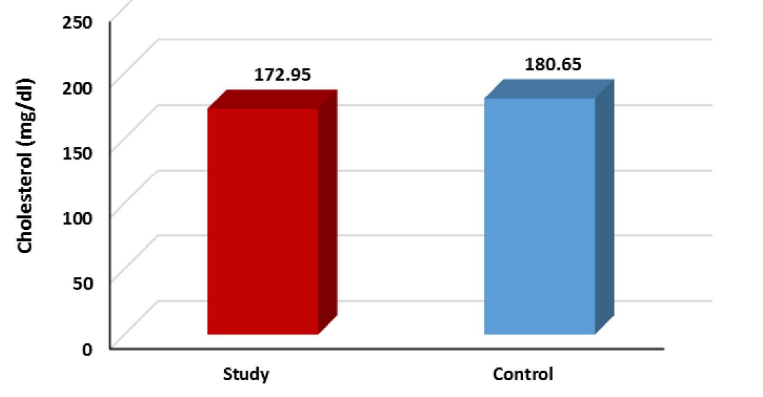

\section{DISCUSSION}

There are many literature data supporting the notion that, abdominal obesity result in alterations in lipids (increased levels of triglycerides and very-low density lipoproteins, and low level of HDL-C), blood pressure, coagulation, fibrinolysis and inflammation, leading to endothelial 
dysfunction and atherosclerosis [11].

The results of this study are supported by Mahgoub et al., 2014 [12]

who found that there were significant differences in waist circumference and waist hip ratio by using ultrasound cavitation more than doing abdominal exercises and diet.

Results of this study agreed with Samantha et al.,2014 [13] who said that high-intensity focused ultrasound effectively decreases waist circumference in Chinese. The higher the total fluency delivered, the larger the decrease in waist circumference was observed.

The results of this study agreed with the results of Mohammed etal., 2014 [14] who found that ultrasound cavitation plus low calorie balanced diet and auricular acupuncture were an effective method for management of obesity but combination of ultrasound cavitation and electrolipolysis plus low calorie balanced diet and auricular acupuncture was more effective than each method alone.

Also the results of the study are supported by Bani et al.,2013 [15] who found that his study further strengthens the current notion that noninvasive transcutaneous ultrasound cavitation is a promising and safe technology for localized reduction of fat and provides experimental evidence for its specific mechanism of action on the adipocytes. Shalom et al., 2013 [16] also said that High-intensity focused ultrasound treatment was well tolerated and safe. Focal damage to target tissue was documented, with adjacent tissues remaining intact.

The results of this study agreed with Nazanin et al., 2013 [17] who approved that there is a reduction in abdominal circumference $2 \mathrm{~cm}$ after a single treatment and the adverse events are limited to transient tenderness, bruising, and edema. As a result, the likelihood of using HIFU for fat reduction will increase over time.

Also Fulvio et al., 2011 [18] in his study demonstrate that ultrasonic is an viable alternative for the treatment of localized fat deposits without the side effects of traditional surgical procedures. Better results are expected when hypotonic solution is used, since it penetrates into the cell.

A total of 152 patients were treated with total
HIFU energy doses of $47-331 \mathrm{~J} / \mathrm{cm} 2$. Post-treat-

ment ultrasonography confirmed that the HIFU effects were limited to targeted SAT layers. The histopathology revealed well-demarcated disruption of adipocytes within the targeted SAT. The lesions were limited to the target area, without evidence of thermal injury to the dermis or the epidermis. Phagocytosis of released lipids and cellular debris occurred between days 14 and 28, and the phagocytized lipids underwent normal hepatic metabolism. The healing progressed normally and was $95 \%$ complete after 8-14 weeks [19].

The result of the study agreed with those of Fateimi,2009 [20] who said that ultrasound cavitation reduce abdominal fat by ablating subcutaneous adipose tissue and causing molecular vibrations that increase the temperature of local tissue and induce rapid cell necrosis resulting in coagulative necrosis of the adipocytes and subsequent reduction of the fat layer.

The results of this study agreed with those of Roustaei et al., 2009 [21] who found that the Ultrasound cavitation easy to produce a liquid implosion effect. Namely, wave expansion and compression form a large number of micro-gap in liquid, which is full of gas and steam; the strong sound waves have position effects on lipid: molecules at compression cycle, while it has vacuum effect at expansion cycle. There is cohesion among liquid and biological tissues, molecular bonding is weak in low density fat cells, and the low vacuum caused by strong sound waves can generate organize gaps, in physics known as the "cavitation" and the implosion caused by micro gaps inside and outside cells will promote molecular motion, makes a high energy level, which finally led to break of fat cells.

The results of the current study are also supported by those of Roustaei etal.,2009 [21] who has found that Cavitation of fat tissues is selectively produced by the $(35-40 \mathrm{KHz})$ emission frequency since the fluid content of said tissues shows better mobilization at this emission frequency than at current frequencies. Furthermore, higher penetration of the ultrasonic wave, higher compression and lower thermal effect are observed. 


\section{CONCLUSION}

Based on the scope and findings of this study, a conclusion declared that using the correct technique, abdominal lipolysis by ultra sonic is a safe and efficacious method and can effectively decrease waist circumference, waist hip ratio and blood cholesterol. It is not a replacement for necessary changes of lifestyle, nor is it a method of weight reduction or a treatment for obesity. The ideal patient is one with small to medium fat deposits that cannot be reduced by exercise and diet.

\section{Conflicts of interest: None}

\section{REFERENCES}

[1]. Sweeting HN. Measurement and definitions of obesity in childhood and adolescence: A field guide for the uninitiated. Nutr J,2007;6(1):32.

[2]. McTigue KM, Harris R and Hemphill B. Screening and interventions for obesity in adults: summary of the evidence for the US Preventive Services Task Force. Ann Intern Med 2003;139:933-49.

[3]. Janssen I, Katzmarzyk PT and Ross R. Body mass index, waist circumference, and health risk: evidence in support of current National Institutes of Health guidelines. Arch Intern Med. 2002 Oct 14;162(18):2074-2079.

[4]. Flegal KM. Obesity, overweight, hypertension, and blood cholesterol: the importance of age. Obes Res., 2000 Dec;8(9):676-7.

[5]. Teitelbaum SA, Burns JL, Kubota J, Matsuda H, Otto MJ, Shirakabe Y, Suzuki Y and Brown SA. Noninvasive body contouring by focused ultrasound: safety and efficacy of the Contour I device in a multicenter, controlled, clinical study. Plast Reconstr Surg. Sep 2007;120(3):779-89; discussion 790.

[6]. Garcia-Murray, E., Rivas, O.A. , Stecco, K.A. The use and mechanism of action of high intensity focused ultrasound for adipose tissue removal and noninvasive body sculpting. Presented at the American Society of Plastic Surgery Annual Meeting. Chicago (IL), September 28, 2005.

[7]. Ter- Haar, G, Coussios, C. High intensity focused ultrasound: physical principle and devices. Int J Hyperthermia, 2007;23: 89-104.

[8]. Kyle M. Coleman, MD, William P. Coleman III, MD, Arie Benchetrit, MD, and FRCS. Non-Invasive, External Ultrasonic Lipolysis, Cutan Med Surg. 2009;28:263-267.

[9]. Chevychase MD. Obesity in America Obesity-Related Diseases: 2011;20815- 301-941-0200.

[10]. Sally M. Ultrasound cavitation versus liposuction in abdominal adoiposity in female. Department of Physical Therapy for Surgery, Faculty of Physical Therapy CairoUniversity Faculty of Physical Therapy CairoUniversity 2012

[11]. Maksimovi'C M., Vlajinac H., Radak D., Mari-Nkovi'C J., Maksimovi'c J. and Jorga1 J. Rela-tionship between Abdominal Obesity and Other Cardio-vascular Risk Factors: Cross Sectional Study of Patients with Symptomatic Carotid Disease. Srp. Arh. Celok. Lek. Jul.-Aug., 2013;141 (7-8): 460-5.

[12]. Mahgoub MS and El- desoky MT. Effect of Cavitation Versus Abdominal Exercise Programs on Abdominal Obese Subjects (Indian journal of Physiotherapy and Occupational Therapy 2014;8(3):7176.

[13]. Samantha YN, Shek CK, Yeung FR, Johnny CY Chan and Henry HL Chan. Efficacy of high - intensity focused ultrasonography for noninvasive body sculpting in Chinese patients lasers in surgery and Medicine 2014;46(4):263-269.

[14]. Mohammed YA, Mohammed HEG and Ezzat MA. Influence of Ultrasound cavitation and electrolipolysis on obesity management. Journal of American Science 2014;10 (9).

[15]. Bani D, Alessandro Q, Freschi G and Russo GL. (2013): Histological and ultrastructural effects of Ultrasound - induced Cavitation on human Skin Adipose Tissue Plastic and Reconstructive surgery Global Open 2013;1(6):41.

[16]. Shalom A, Wiser I Brawer S, Azhari H. (2013): Safety and Tolerability of a Focused Ultrasound Device for Treatment of Adipose Tissue in Subjects Undergoing Abdominoplasty: A Placebo - Control Pilot Study Dermatolgic Surgery 2013;39(5):744-751

[17]. Nazanin S and Michael K. SeminCutan Med Surg 2013;32: 26-30 Frontline Medical communications.

[18]. Fulvio BG Belchiolina BF, Marcelo AL, Mariane AF, Roberta TM and Marcelo EB. Sturctural Changes of Fat Tissue After nonaspirative Ultrasonic hydrolipoclasy J Cutan Aesthet Surg. 2011Aug;4(2): 105-110.

[19]. GADSDEN E., AGUILAR M.T. and SMOLLER B.R. Evaluation of a novel highintensity focused ultrasound device for ablating subcutaneous adipose tissue for non-invasive body contouring: Safety studies in human vol-unteers. cAesthet. Surg. J. 2011;31:40110.

[20]. Fatemi A. High-intensity focused ultrasound effectively reduces adipose tissue. S-thetic Clinic Düsseldorf, Düsseldorf Germany. Am J Clin Nutr. 2009Apr; 89(4):1043-52

[21]. Roustaei N, Masoumi Lari SJ, Chalian M, Chalian H, Bakhshandeh H. Safety of ultrasound-assisted liposuction: a survey of 660 operations. Aesthetic plastic surgery. 2009 Mar 1;33(2):213-8.

How to cite this article: Mohamed Hussien ElGendy, Abir Zakaria Mohamed, Yasser Ramzy Lasheen, Mustafa Awad Ali Awad. EFFICACY OF ULTRASONIC LIPOLYSIS ON BLOOD CHOLESTEROL LEVEL IN CENTRALLY OBESE WOMEN. Int J Physiother Res 2017;5(4):21642170. DOI: $10.16965 /$ ijpr.2017.163 